\title{
Participation of the students of Riga Technical University in the Olympiad in mathematics
}

\author{
Cernajeva, Sarmite and Volodko, Inta \\ Department of Engineering Mathematics, Riga Technical University, Latvia.
}

\begin{abstract}
There is much discussion recent years about teaching mathematics at school and universities. It is talked about how to interest pupils and students to turn to studying mathematics more. One of the ways to attract the best students to additional studies of mathematics is to invite them to participate in the Olympiads in mathematics. Student Parliament of Riga Technical University in cooperation with the Department of Engineering Mathematics organized the university Olympiad in mathematics for 6 years. There is an international Olympiad of mathematics in Latvia already for 6 years, which is organized by the Department of Mathematics of Latvia University of Agriculture. Students from Baltic universities participate in these Olympiads, and within their scope, students not only compete individually, but also discuss among themselves the content of mathematics and teaching methodology in their universities, evaluate it and express their suggestions for the improvements. Since 2012, students from Riga Technical University also participate in these Olympiads and get award-winning places. Such Olympiads promote interest about mathematics among young people, develops cooperation skills between like-minded people, as well as, give an opportunity for pedagogues to listen to the opinion of the best students about teaching methodology of mathematics and to improve it.
\end{abstract}

Keywords: Olympiad of mathematics for students, promotion of interest in mathematics, improvement of teaching methodology of mathematics. 


\section{Introduction}

There is much discussion recent years about teaching mathematics both at school, and universities. Up until now, mathematics in universities was viewed as a tool for a successful acquisition of other subjects, but now, a question about the use of the acquired mathematical knowledge in the professional actions of the specialists is becoming topical. Answers to these questions are being searched for: what is it that needs to be taught, and how it should be done so that the acquired knowledge is useful for the professional work. To attract students to the studies of mathematics, Riga Technical University (RTU) had Olympiads in mathematics for 6 years. Latvia University of Agriculture, to promote the attractiveness to the studies of mathematics among young people, for the last six years also has an international Olympiad for students, which is organized by the Department of Mathematics. This Olympiad is one of the activities, which follows from an international cooperation agreement in the sciences that was signed between deans of the University of Siauliai, Faculty of Mathematics and Information Technologies and Latvia University of Agriculture, Faculty of Information Technologies on $14^{\text {th }}$ December, 2012.

\section{Short overview about the history of Olympiads in mathematics in Latvia}

The beginnings of the Olympiads in mathematics for secondary schools can be searched in academic year 1945/ 1946, when the Department of Mathematics of the State University of Latvia (now University of Latvia) organized the first Olympiad. This type of mathematical contest for pupils happens regularly since the academic year 1949/1950, but the numbering of the Olympiads began with the academic year 1950/1951, when the castle of Riga Pioneers (now castle of Riga Pupils) took part in its organization (http://nms.lu.lv/ olimpiades/olimpiazu-rasanas/ ). Pupils Olympiads of mathematics happen also nowadays, they happen in different levels, starting with school Olympiads in mathematics, then city, country and state Olympiads in mathematics. In 2017, 5 pupils from Latvia took part in an international Olympiad of mathematics in Brazil. To attract students to additional studies of mathematics, RTU Student Parliament in cooperation with Department of Engineering Mathematics organized students' Olympiad of mathematics in 2006. These Olympiads happened for 6 years, but, with the decrease of interest from students, were stopped.

Whereas, tradition to organize an International students' Olympiad in mathematics was established in 2011, in frames of a cross-border cooperation project between Latvia Lithuania "Cross-border cooperation net to include the competences of mathematics in the social economical development of the region" (MATNET), and this year it was organized for the $6^{\text {th }}$ time. 
The aim of the Olympiad is to promote interest in mathematics among young people, strengthen the education gained at school, ensuring a creative way using it, as well as, promote cooperation skills between young people with similar interests. That is why, to take part in the Olympiad are those who are good at mathematics, who are interested in a problem of a specific matter, who like "hard nuts", as well as, all those who wish to try out their strength in mathematical contest.

At the beginning the Olympiad was organized only for students from the University of Siauliai and Latvia University of Agriculture. Then the next year students from Riga Technical University also joined. Number of participants of the Olympiad in the last two years has grown. Last year there was 81 participants from 18 educational institutions.

\section{Olympiads of mathematics in Riga Technical University}

The biggest "stumbling block" in Riga Technical University, as in other technical universities, is general subjects - mathematics and physics. In 2006, RTU Student Parliament came with an idea to organize students' Olympiad in mathematics and physics with an aim to interest students in acquiring these subjects. Teaching staff of the Department of Engineering Mathematics supported this idea and were willing to create tasks and evaluate students' works. Responsiveness from students was unexpectedly huge. At the beginning there were more than 200 students who applied for the Olympiad, that is why, it was decided to organize a selection round, and only the 50 best ones send to the final. Though, not all the students who had applied for the Olympiad came to the selection round. Number of participants of the Olympiad in years from 2006 to 2011 is seen in Figure 1.

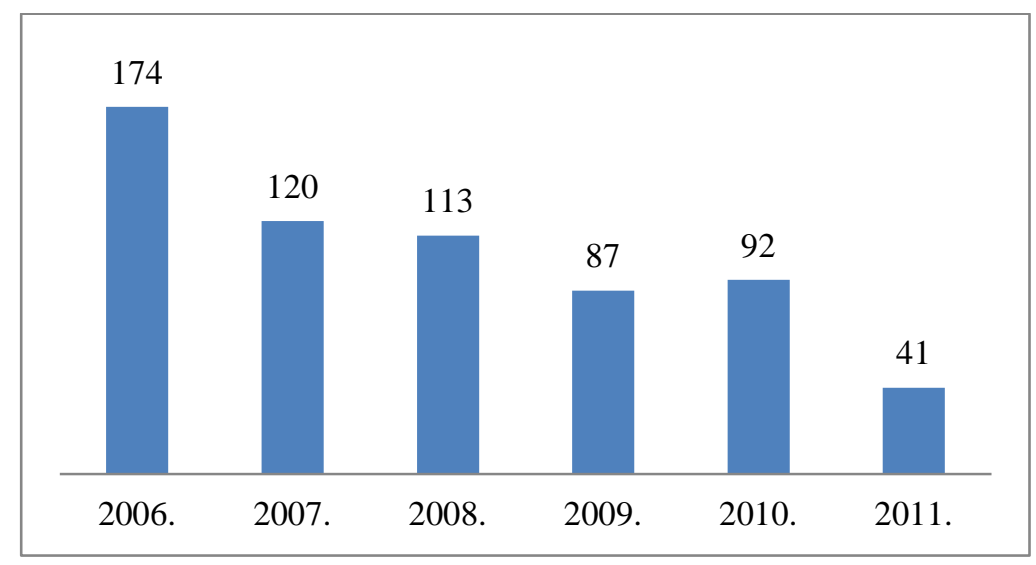

Figure 1. Number of participants of the RTU Olympiad in mathematics. 
As it is seen from the Figure 1, interest from students started to disappear, that is why, organization of the Olympiad in mathematics (also in physics) was stopped. Now we are thinking of renewing this experience, but, in a new, different way, maybe by organizing team contests.

Parallel to students' Olympiad in mathematics, there was also an online Olympiad for pupils, where pupils were offered to solve the same tasks. Interest from pupils about the Olympiad was rather high - about 200 pupils sent in their works every year. These online Olympiads in mathematics promoted interest in mathematics and Riga Technical University.

\section{International Olympiad of mathematics in Latvia}

As mentioned before, International Students' Olympiad in mathematics in Latvia is held once a year since 2011, and main organizers are Department of Mathematics in Latvia University of Agriculture (LLU). Students from Riga Technical University participate in these Olympiads since 2012, in addition, showing good results and receiving some of the award-winning places every year.

In 2017, 81 participant applied to participate in the Olympiad from 18 different educational institutions: 22 local (LLU) students, 19 students from Lithuania (University of Siauliai and University of Alexander Stulginsky), 3 students from Estonia (EMU), as well as, students from several universities from Latvia, such as, Riga Technical University (RTU), Ventspils University College, Liepaja University, and LLU Erasmus+ exchange students from Portugal (Instituto Politecnico Braganca) also took part in the Olympiad.

As the level of Olympiad does not exceed secondary school knowledge but knowledge gained at university can be used - system of equations and extremes, pupils from cooperation secondary educational institutions of Faculty of Information Technologies of LLU were invited to participate for the third year. This year pupils from 7 Secondary school participated in the Olympiad. Olympiad was organized in 2 parts. First part includes individual contest and is an hour long. There were some jigsaw puzzles included, but the second part - group work. Groups are selected randomly at the time, so that there are different educational institutions represented in the group. Work in teams of five - seven students involved solving the schemer geometry tasks, as well as, linking students' hobbies with the validation of mathematics. Group work also includes experience exchange between students about learning and teaching of mathematics at their universities, what is common, what is different, as well as, what is good, what should be improved in the study process. 
Individual tasks each country had in their own language, group tasks - in Latvian, Lithuanian and English, communication between students - in English.

Starting from 2012, RTU students participate in these Olympiads every year, and every year receive award-winning places. Although, last year the first prize received a student from the Faculty of Physics and Mathematics of University of Latvia, but in the total evaluation of the teams, RTU received the highest points. Received points of each team can be seen in Figure 2, abbreviation under the graphics mean: RTU - Riga Technical University, LLU - Latvian University of Agriculture, LU - Latvian University, VA Ventspils University College, LiepU - Liepaja University, ASU - Aleksandra Stulginska University (Lithuania), Siauliai University (Lithuania), EMU - Estonian University of Life, IPB - Polytechnic Institute Braganca (Portugal).

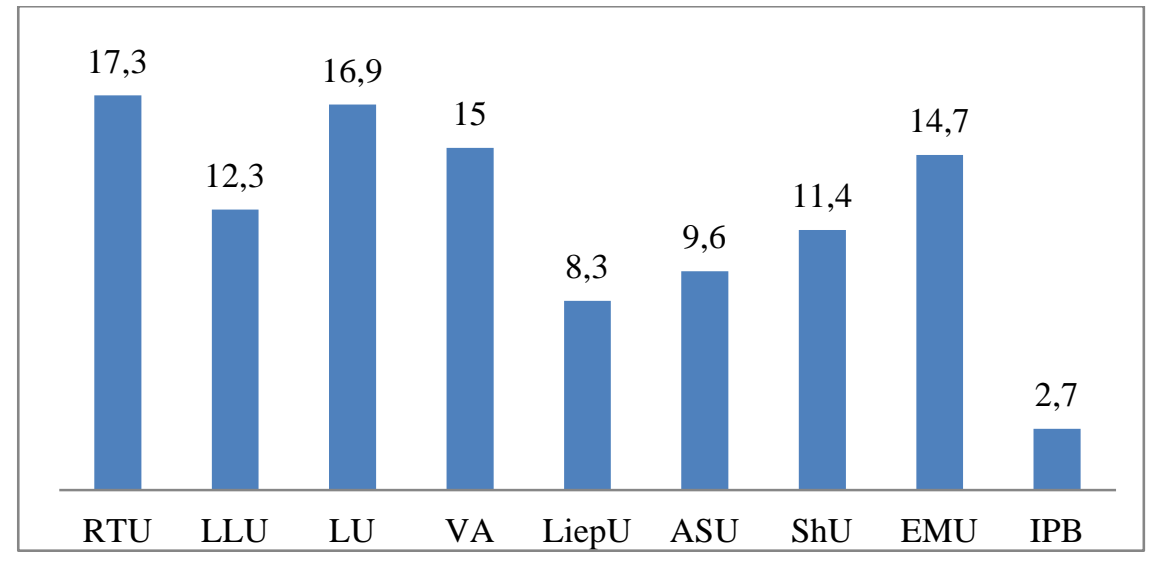

Figure 2. Average points that each university team received in the Olympiad.

Teams were given additional tasks, too - share their experiences about math studies, set common and different in the mentioned educational institutions, as well as, express their suggestions to improve mathematical studies. The link of the course of mathematical studies with real life situations and usage of the acquired knowledge is the main topic for discussions. To improve the studies of mathematics, students suggest customizing the course of mathematics to a certain specialty, use more interactive materials, as well as, simulation and logic tests and tasks. In turn, theoretical approach promotes general skills in their opinion. Interesting is also a fact that both students from LLU, and RTU see the necessity of mathematical studies, but students from Siauliai University and Technical school of Jelgava doubt the usage of taught mathematics to them in future. Students from Vidzeme University find only some topics interesting and useful in their chosen profession.

Common in mathematical studies in all universities are homework, tests, practical works in relatively small groups, as well as, access to an electronic study materials (e-studies and other study platforms). Although, homework is a requirement for credit points in several 
universities, in RTU they are evaluated and give extra points. Students admit that it makes it easier to get a successful evaluation of the course. RTU students also welcome additional course to revise secondary school knowledge. These courses are compulsory for those students who have failed test about elementary knowledge of mathematics. But, other students are also allowed to attend these courses both to revise the forgotten secondary school topics, and to acquire topics of higher mathematics additionally.

It should be noted that for the Siauliai University, the highest value is a student friendly environment, access to technologies, good relationship with teaching staff, also the fact that pedagogues are very welcoming and during the study process give a lot of good examples. In turn, students from Vidzeme University are surprised that pedagogue not only asks if all students understood everything and if there are any suggestions or wishes after the lectures, but also take their suggestions into consideration.

After the discussion, students confidence strengthen that mathematics is not only a complicated and precise science, which is necessary for scientific researches, but it is also used in everyday life. To improve mathematical studies, students suggest varying tasks that are offered for an individual work, in practical classes create even smaller groups to have all students being involved, as well as, use more visual materials. Students would also like a slower pace of the studies.

Interest about the Mathematics Olympiad grows every year. The number of participants has been limited and has remained in the range of 55 - 64 students for all eight years as merely one hour has been provided for assessment of an each work. Nonetheless, the number of Universities sending students to the Olympiads is increasing almost every year. The number of Universities participating in the Olympiads is depicted in the Figure 3.

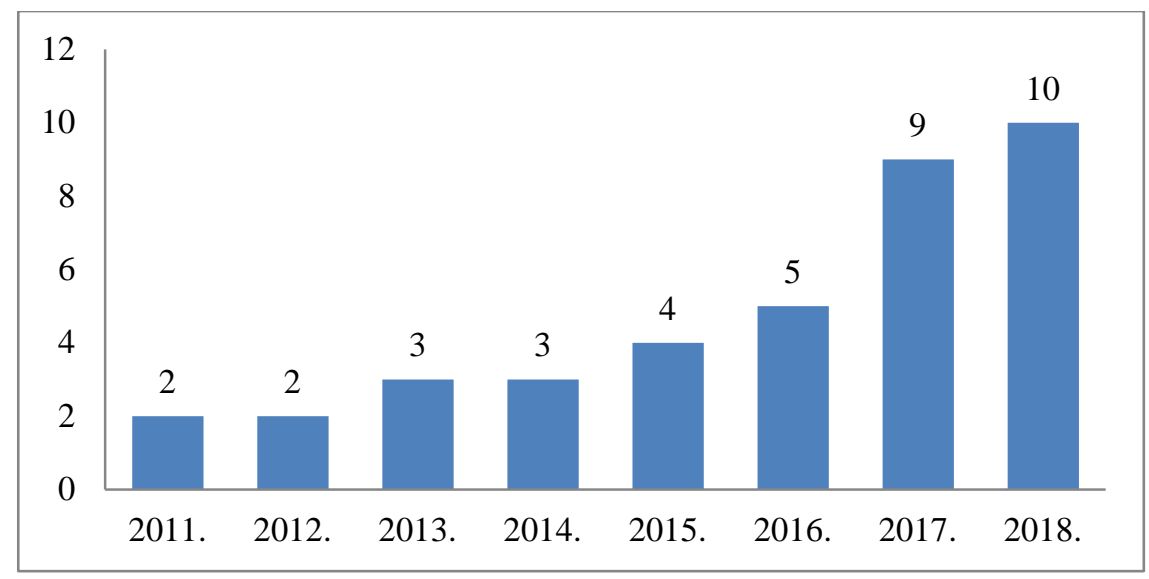

Figure 3. The number of Universities participating in the Olympiads from 2011 to 2018. 
Ability of finding smart solution to the mathematical problems not only eases students' everyday life, but also smooth the way of finding a job. Many organizations require potential employees filling out tests prior to a job interview, which usually contain mathematical problems as well. For example, the European Personnel Selection Office requires filling the pre-selection tests when looking for new staff for the EU institutions. Among the others, there are included ten mathematical problems, which shall be solved within 20 minutes. These problems are used for testing the following mathematical abilities: data interpretation, reasoning, estimation, calculation. Some mathematical problems of the Olympiads are similar to the ones included in these tests. Consequently, participation at the Mathematics Olympiads not only develops students' abstract and logical thinking, but also trains them "think smart", which in turn facilitates their abilities of finding a prompt solution to the tests of this kind.

In the International Olympiad in Jelgava, not only students get some new insight, but also pedagogues. Firstly, a lot can be taken from students' evaluation on curriculum of the mathematical subject, evaluation of the teaching and their suggestions for improvement. Secondly, parallel to the Olympiad, there was a seminar-discussion for mathematics teachers and pedagogues about mathematical education at university in context of sustainable development. Starting with next academic year - 2018/2019, a gradual change to a perfected curriculum and an appropriate changed teaching approach will begin in schools and per-schools of Latvia (from age of 1.5 to 18), for students to, as a result, develop "necessary knowledge, skills and abilities for life in the $21^{\text {st }}$ century" (school 2030). Project of the State Education Content Centre (SECC) "Competence approach in the curriculum” foresees to create support mechanisms in five years period for schools, municipalities and parents for a successful change of the teaching approach (https://www.skola2030.lv/ 2017.15.09.). The shift of a paradigm in the school study program will create a row of changes both in university programs of mathematics, and their implementation.

While implementing the competence approach, study program of the subject will remain, but teachers' cooperation in a school level, in planning the work and its implementation will increase. "Changes are necessary because pupils have changed themselves!" (http://www.iespejutilts.lv/ 2017.20.09.) It is essential to switch from giving a ready knowledge and a frontal learning form, where pedagogue gives information in front of the class, to a leading the learning, teach and learn differently is possible already in frames of an existing curriculum, and in many schools it is already happening. 


\section{Conclusions}

1. Olympiads in mathematics promote interest about mathematics among young people, develops cooperation between like-minded young people.

2. International Olympiad for students is an example of good practice for a sustainability of the results of international projects.

3. International Olympiads for students, where students can share their experience about mathematical studies and express their suggestions for the improvement of the mathematical studies, give pedagogues a chance to listen to the opinion of their best students about methodology of teaching mathematics and improve it.

\section{References}

http://nms.lu.lv/olimpiades/olimpiazu-rasanas/ (In Latvian)

https://www.skola2030.lv/ (2017.15.09.) (In Latvian)

http://www.iespejutilts.lv/ (2017.20.09.) (In Latvian) 